\title{
Erratum to: A brief assessment tool for investigating facets of moral judgment from realistic vignettes
}

\author{
Michael Kruepke $^{1} \cdot$ Erin K. Molloy ${ }^{2} \cdot K_{\text {Konrad Bresin }}{ }^{1} \cdot$ Aron K. Barbey $^{3}$. \\ Edelyn Verona ${ }^{4}$
}

Published online: 17 July 2017

(C) Psychonomic Society, Inc. 2017

Erratum to: Behav Res

DOI 10.3758/s13428-017-0917-3

On page 3, left-hand column, last paragraph, the fourth sentence should be changed to "This concern could be further compounded by not reporting which vignettes were used, including one of the two published studies that have used Knutson's stimuli (Simpson \& Laham, 2015)".

The online version of the original article can be found at http://dx.doi.org/ 10.3758/s13428-017-0917-3

Michael Kruepke

mdkruepke@gmail.com

1 Psychology Department, University of Illinois at Urbana-Champaign, Urbana-Champaign, Champaign, IL 61820,

USA

2 Computer Science Department, University of Illinois at Urbana-Champaign, Urbana-Champaign, IL, USA

3 Beckman Institute for Advanced Science and Technology, University of Illinois at Urbana-Champaign, Urbana-Champaign, IL, USA

4 Psychology Department, University of South Florida, Tampa, FL, USA 